Hofmann, Alexander; Laqua, Daniel; Husar, Peter:

Piezoelectric based energy management system for powering intelligent implants and prostheses

Zuerst erschienen in: $\quad$ Biomedical Engineering = Biomedizinische Technik. - Berlin [u.a.] : de Gruyter. - 57 (2012), Suppl. 1, Track-S, p. 263-266.

Erstveröffentlichung: 2012-09-06

ISSN (online): $\quad$ 1862-278X

ISSN (print): $\quad$ 0013-5585

DOI: $\quad 10.1515 / \mathrm{bmt}-2012-4265$

[Zuletzt gesehen: 2019-08-15]

„Im Rahmen der hochschulweiten Open-Access-Strategie für die Zweitveröffentlichung identifiziert durch die Universitätsbibliothek IImenau. “

"Within the academic Open Access Strategy identified for deposition by Ilmenau University Library."

„Dieser Beitrag ist mit Zustimmung des Rechteinhabers aufgrund einer (DFGgeförderten) Allianz- bzw. Nationallizenz frei zugänglich."

"This publication is with permission of the rights owner freely accessible due to an Alliance licence and a national licence (funded by the DFG, German

Research Foundation) respectively." 


\title{
Piezoelectric Based Energy Management System for Powering Intelligent Implants and Prostheses
}

\author{
Alexander Hofmann, Daniel Laqua, Peter Husar Senior Member, IEEE
}

\begin{abstract}
The use of body given, self-sufficient energy sources can improve intelligent implants and prostheses to reduce stressful post-operations and check-ups. Energy harvesting using piezoelectric generators (PG) could take advantages of any movement of or in the human body to provide enough energy for wireless sensor-, processing- and communicationunits of these medical applications. The limited environmental power and space complicate the realisation of an efficient energy conversion process. These conditions put high requirements not only on the piezoelectric material and its manufacturing technology but also on the whole power management. This work presents a completely self-sustaining, piezoelectric energy harvesting management system using a DC/DC step-up converter, a battery charger component and a rechargeable battery. The System is self-controlled by a MOSFET-based circuitry, and works with different electronic loads even when piezoelectric energy supply is missing.
\end{abstract}

\section{INTRODUCTION}

The worldwide rising energy deficiency requires a progressive developement of new concepts of power generation, which concerns not only the primary supply but also medical applications. Intelligent implants and prostheses will not only recover main functions of organs and extremities with disorder any longer. In future wireless sensor-, processingand communication-units of these medical applications will help to record and notify complications and disfunctions early on, what may help to reduce stressful post-operations and check-ups. A stride towards a more independent and mobile life of patients with these medical applications will be a self-sufficient power supply providing all necessary electronic components. The process describing the power conversion of any environmental energy into electrical power is called "energy harvesting". These concepts also include the use of piezoelectric generators that could take advantages of any movement of or in the human body. The muscles, the lung and the pleura, the eye, the vessels or human movement are just some examples that can work as power sources in combination with piezoelectric generators. Piezoelectricity is an electromechanical conversion process that describes the mutual coupling between stress/strain and electrical charge/field. The elastical deformation of piezoelectric active material causes a change of polarization. This so called

This work was supported by the BMBF

A. Hofmann is with the Institute of Biomedical Engineering and Informatics, Ilmenau University of Technology, Ilmenau, 98693 Germany (e-mail: alexander. hofmannetu-ilmenau.de)

D. Laqua is with the Institute of Biomedical Engineering and Informatics, Ilmenau University of Technology, Ilmenau, 98693 Germany (e-mail daniel. laquadtu-ilmenau.de)

P. Husar is with the Institute of Biomedical Engineering and Informatics, Ilmenau University of Technology, Ilmenau, 98693 Germany (email:peter.husardtu-ilmenau.de)

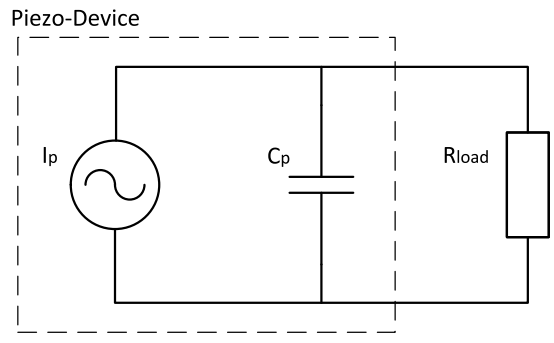

Fig. 1. Equivalent circuit diagram of a piezoelectric generator as current source configuration with $I_{p}$ the alternating current, $C_{p}$ the internal capacitance of the PG and $R_{\text {load }}$ the following load in parallel with the source. [1]

direct piezoelectric effect is known since 1880 and nowadays industrially used for piezoelectric sensors.

Depending on the interconnection of piezoelectric layers a PG can be seen as current or voltage source. Figure 1 shows the equivalent circuit of a piezoelectric generator as current source in parallel configuration.

The developement and optimization of piezoelectric energy harvesting is described in [2], [3] and [4]. Especially [4] shows the complexity of low power piezoelectric energy harvesting systems, where high system efficiency depends on many factors such as the use of optimum loads, constant and harmonic excitation. On the contrary in piezoelectric energy harvesting for powering intelligent implants and prostheses optimal loads and harmonic excitations cannot be expected. The space constraint, biocompatibility and patient safety take priority, so that piezoelectric energy harvesting systems could temporarily not get access to sufficient energy. This paper presents a state-of-the-art self-sustaining piezoelectric energy management system, working with different kinds of electronic loads under disharmonic excitation even when piezoelectric energy supply is missing.

\section{MATERIAL AND METHODS}

The basic concept of the whole device is shown in figure 2. The piezoelectric generator V22B produced by Mide Technology represents the energy source. It has a small size of $35.56 \times 6.1 \times 0.64 \mathrm{~mm}$ and a frequency range of $120 \mathrm{~Hz}$ to $360 \mathrm{~Hz}$. The parallel configuration was chosen, which connects the two included piezoelectric layers in parallel to provide enough input-current for the harvester device. [1]

The harvesting module LTC3108 produced by Linear Technology is the central element. It is a highly integrated DC/DC step-up converter with an internal rectifier which only needs low AC-input voltages of $20 \mathrm{mV}$. Therefore an external component such as a transformer is needed, which 
was not used for the experimental setup. However it also requires an input current of $3 \mathrm{~mA}$ for operating conditions. The output DC-voltage can be adjusted to $2.35 \mathrm{~V}, 3.3 \mathrm{~V}$, $4.1 \mathrm{~V}$ and $5 \mathrm{~V}$. For the experimental setup $5 \mathrm{~V}$ was chosen. The work [5] shows the functionality of both parts in combination. [6]

Staionary phases of movement will result in a lack of power, where electronic components of intelligent implants and prostheses cannot be supplied. Hence, the system consists of an additional shunt battery charger, the LTC4070, and the rechargeable battery $\mathrm{CBC} 050$ to bridge short interrupts of energy supply. The LTC4070 by Linear Technology is an integrated charger system for Li-Ion/Polymer batteries that only needs $450 \mathrm{nA}$ operating current. The float voltage can be set to $4.0 \mathrm{~V}, 4.1 \mathrm{~V}$ and $4.2 \mathrm{~V}$, which enables an optimum balance between battery capacity and lifetime. The charge current can be increased by additional components from $50 \mathrm{~mA}$ to $500 \mathrm{~mA}$, which are also the maximum values that are shunted, when the battery reaches its maximum output voltage. Therefore the battery can be protected against damage. The EnerChip CBC050 by Cymbet Corporation is a small sized rechargeable solid state energy storage, with a capacity of $50 \mu \mathrm{A}$, an output voltage of $3.8 \mathrm{~V}$ and a cutoff voltage of $3.0 \mathrm{~V}$. [7], [8]

There are two operating conditions of the system. The excitation of the V22B results in the startup of the LTC 3108. The harvester begins to rectify the AC-input voltage and converts it to the adjusted DC-output voltage to supply connected loads. At the same time the battery will be charged. The LTC4070 controlls the load voltage and shunts current to ground if the battery reaches its maxmimum output voltage. So the battery can be protected against overvoltage. A circuitry (figure 3 ) used for switching between the two DCpower sources of the system consists of two p-MOSFETs and one n-MOSFET. If the V22B provides enough piezoelectric energy, the LTC3108 generates enough DC-output power. The n-MOSFET T3 opens at its treshold voltage and enables the energy supply of external components. At the same time the second path with connection to the battery is closed because the output voltage of the harvester is connected to the gate of the p-MOSFET T2. During stationary phases the harvester cannot generate enough energy. Therefore T2 opens and T3 is closed. The battery can supply connected loads for a short period of time until the output voltage of the battery deceeds the treshold voltage of $\mathrm{T} 2$. The battery is not connected to external components any longer and will be protected against deep battery discharge. The power management components also consume a quiescent current that can completely discharge the battery. Therefore the output voltage of the battery is connected to the gate of the p-MOSFET T1. Once the battery reaches the treshold voltage of $\mathrm{T} 1$, the MOSFET will be closed to prevent internally discharge.

The whole power management system has a size of approximately $23 \times 26 \mathrm{~mm}$ using a double-sided PCB.

To test the functionality of the system different loads were connected such as the temperature sensor TMP20 and the microcontroller MSP430F2274 by Texas Instruments. The

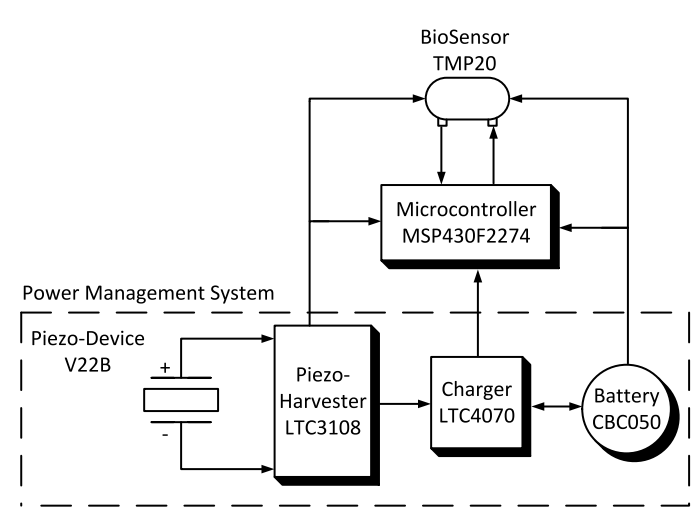

Fig. 2. Basic concept of the highly integrated measurement system with the temperature sensor TMP20, the microcontroller MSP430F2274 and the piezoelectric based power management circuitry consisting of the piezoelectric device V22B, the harvester LTC3108, the charger LTC4070 and the battery $\mathrm{CBC} 050$.

energy management system provides enough power to supply the TMP20, which needs the electrical power of $9 \mu \mathrm{W}$ and the MSP430F2274 with a maximum energy consumption of $7 \mu \mathrm{Ws}$ performing an $\mathrm{A} / \mathrm{D}$-conversion process to read temperature values about every eight seconds. [9], [10]

\section{RESULTS}

\section{A. Oscillation of the Piezoelectric Generator}

The piezoelectric generator V22B was continously excited by deflection of a few millimeters for approximately 13 minutes. An electric motor with a coupled unbalance was used as actuator. The measurement results are presented in figure 4. The graph shows the piezoelectric oscillation for five minutes. Within the first 3.5 seconds the power management system and the loads were not connected to the PG. For that reason the piezoelectric generator produces voltages of around $14 V_{p p}$. Between second 3.5 to 3.6 the power management system and the loads were connected to the source. This results in a breakdown (figure 5) of the piezoelectric voltage to $2.5 V_{p p}$, because of the current consumption. From second 50 to 120 the piezoelectric voltage begins to stabilize up to $4.5 V_{p p}$. Figure 6 shows the frequency domain of the oscillating source. Expectedly there are some bigger peaks at $14 \mathrm{~Hz}$ according to the rotation frequency of the actuator which is well below the operating frequency of the V22B. The disharmonic rotation caused by the unbalance of the actuator leads to a PG specific resonance behavior with faster oscillations. Hence, there is a greater, more dominant peak at $150 \mathrm{~Hz}$.

\section{B. Generated DC-Output Voltages}

Figure 7 illustrates the generated output voltage $V_{\text {out }}$ of the LTC3108 (upper graph), the battery voltage $V_{\text {batt }}$ (middle graph) and the system output voltage $V_{\text {load }}$ to provide the loads (lower graph). At the beginning of piezoelectric oscillation all voltages start to rise until they reach $1.8 \mathrm{~V}$, which is the minimum voltage treshold for the MSP430F2274 to reach operating condition. From minute 1 to 1.5 the voltages stop rising for a short period of time until the system can provide enough energy to supply the loads. At the third minute 


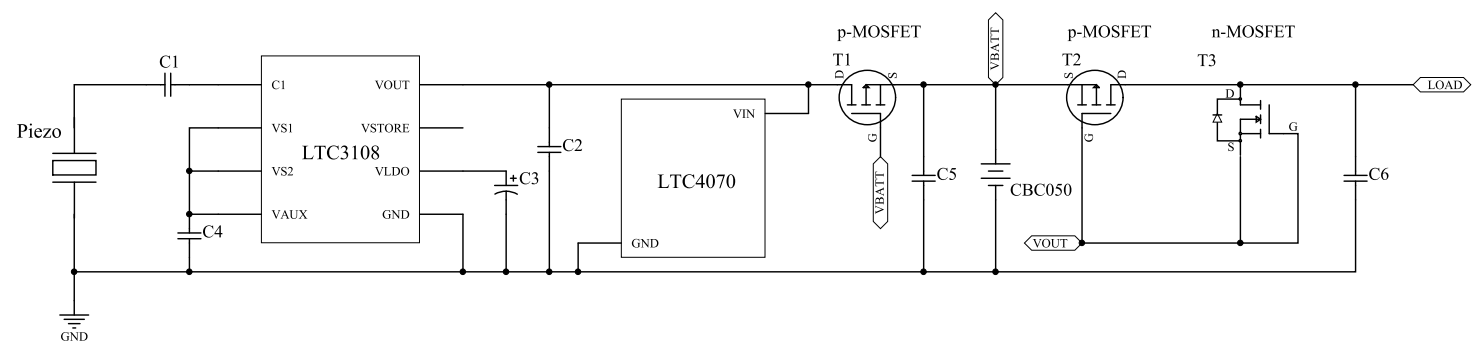

Fig. 3. Equivalent circuit of the power generating system with the piezoelectric element V22B, the energy harvester LTC3108, the battery charger LTC4070, the battery CBC050 and the MOSFET realized power switch.

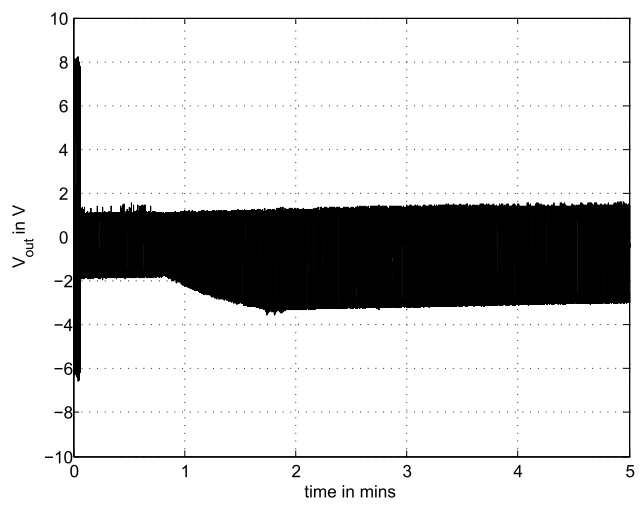

Fig. 4. Produced AC-output voltage of the piezoelectric generator V22B as a function of time depending on the elongation according to the applied force.

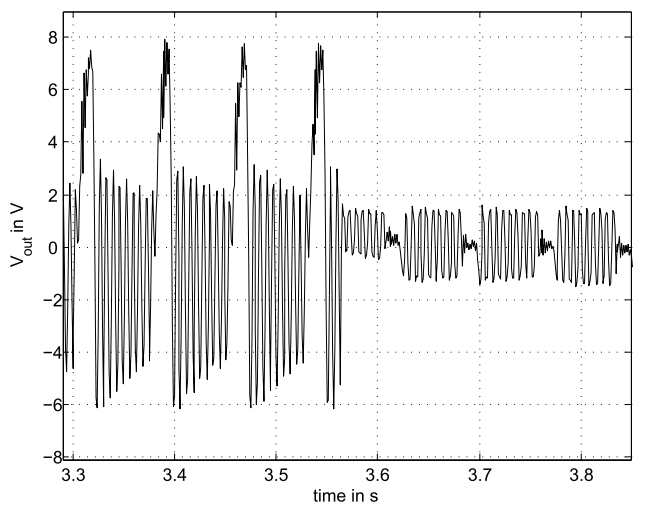

Fig. 5. Collapsed piezoelectric AC-output voltage as a function of time due to the added loads.

the still increasing voltages finally reach their maximum. Figure 8 represents typical signal curves of the generated DC-voltages. In the upper graph $V_{\text {out }}$ is shown which reaches $4.1 \mathrm{~V}$ despite the adjusted limit of $5 \mathrm{~V}$. This is exactly the maximum battery float voltage that can be reached, because the battery charger shunts current to ground to protect the battery at that point. $4.1 \mathrm{~V}$ is also the maximum supply voltage of the microcontroller. The lower graph shows the actual load supply voltage with a maximum of ca. $3.7 \mathrm{~V}$. The n-MOSFET evokes a voltage drop of ca. $0.4 \mathrm{~V}$ and protects the MSP430F2274 against overvoltage. The periodic ripple that can be found in the lower graph of $V_{\text {load }}$ as well

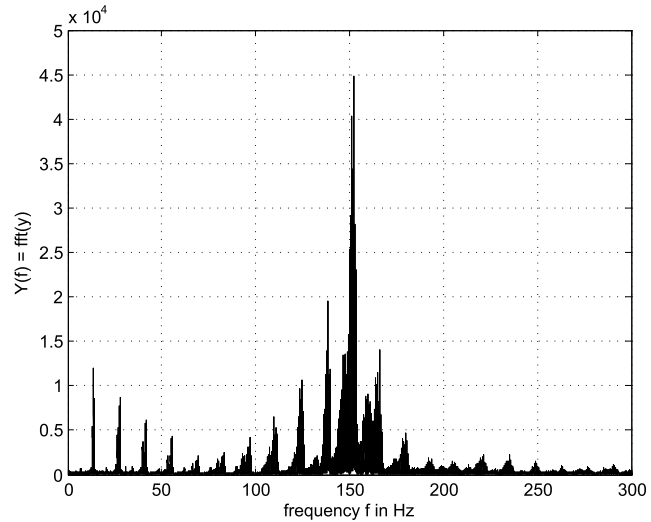

Fig. 6. Frequency domain of the oscillating piezoelectric generator. The maximum frequency peak is at $150 \mathrm{~Hz}$. Another frequency peak can be found at $14 \mathrm{~Hz}$ because of the applied rotation frequency of the actuator.
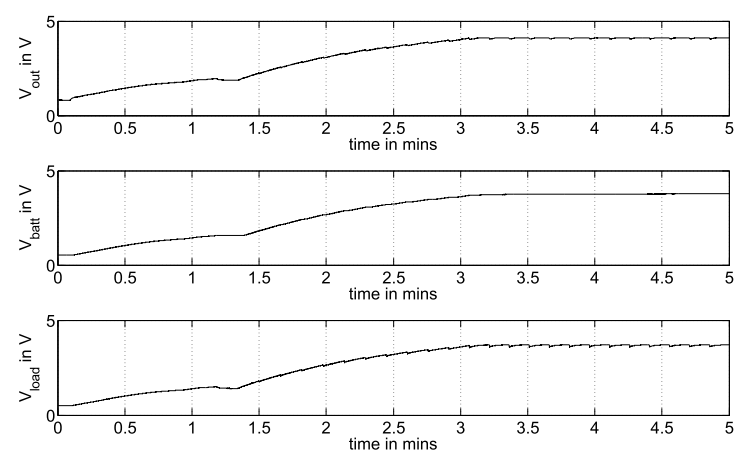

Fig. 7. Rising DC-voltages $V_{\text {out }}$ (upper graph), $V_{\text {batt }}$ (graph in the middle) and $V_{\text {load }}$ (graph below) as functions of time up to their maximum values.

represents the A/D-conversion process that is done about every eight seconds. The middle graph with $V_{\text {batt }}$ does not show these ripples, because the battery is not yet connected to the loads. Therefore $V_{b a t t}$ still rises to its maximum value of $3.8 \mathrm{~V}$.

\section{DC-Output Voltages after Excitation Break-off}

The excitation of the PG was stopped after 13 minutes, which can be seen in figure 9 . Consequently $V_{\text {out }}$ decreases rapidly (upper graph) until $V_{\text {out }}$ reaches $0 \mathrm{~V}$. Within two minutes the harvester is not able to supply the loads any longer. But $V_{\text {load }}$ (second graph from below) does not decrease that fast, because the battery steps in after 14.25 

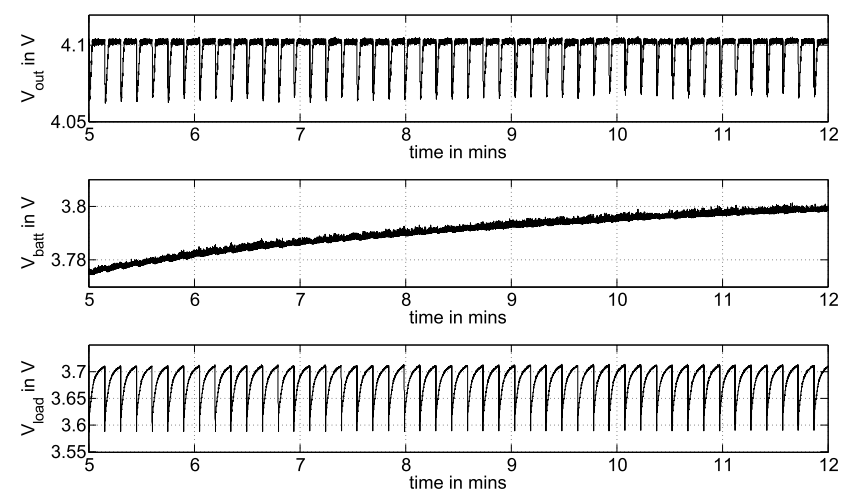

Fig. 8. Typical ripple output voltage $V_{\text {out }}$ (upper graph) and load supply voltage $V_{\text {load }}$ (graph below) as functions of time and the steadily increasing battery voltage $V_{\text {batt }}$ as a function of time (middle graph).
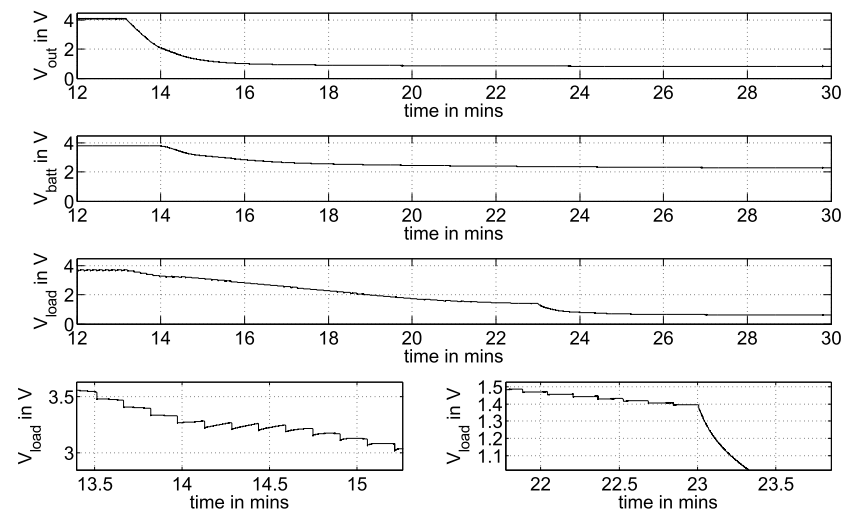

Fig. 9. Falling DC-voltages $V_{\text {out }}$ (upper graph), $V_{\text {batt }}$ (second graph from above) and $V_{l o a d}$ (second graph from below) as a function of time when excitation stops. The DC-voltage $V_{\text {load }}$ as functions of time when the battery steps in (lower graph on the left side) and when the system locks out (lower graph on the right side)

minutes, which is shown in the lower graph on the left side. From minute 14.25 to $14.7 V_{\text {load }}$ seems to become stable with partially steeper ripples. The battery provides the loads for ten minutes without any piezoelectric energy supply until the system disconnects the loads (lower graph on the right side) and $V_{\text {load }}$ converges to $0 \mathrm{~V}$. $V_{\text {batt }}$ (second graph from above) levels off at $2.2 \mathrm{~V}$. So the battery is protected against undervoltage. The slight decrease of $V_{\text {batt }}$ after 23 minutes can be a result of the MOSFET leakage current that flows to electronic components.

\section{DISCUSSION}

Although a relatively high startup piezoelectric input voltage of $14 V_{p p}$ is needed, only small excitations of a few millimeters were applied. Furthermore the rotation frequency of the actuator was far below the original operating frequency of the V22B.

The disharmonic excitation did not negatively affect the stability of the generated DC-output voltages or the piezoeletrical material. Despite the applied experimental setup cannot simulate everyday conditions the system is able to handle disharmonic excitations and to supply sensor- and processing units.
Discontinuities in the DC-signal curves correspond to the system behaviour, which includes interaction between the piezoelectric generator, the power management system and the coupled loads.

The slight decrease of $V_{\text {batt }}$ after disconnecting the loads can be difficult concerning longer periods of missing PG excition. Hence, the battery could also be completely discharged.

\section{CONCLUSIONS AND FUTURE WORK}

This work presents a highly integrated piezoelectric energy management system generating sufficient energy to provide an ultra-low power measuring system with only a small amount of external components.

Further work will imply the use of faster switching MOSFETs with a lower leakage current. Another energy storage with a wider output voltage range has to be considered too.

The system performance in combination with further loads such as RF-transceivers will be investigated.

A more application oriented experimental setup should be realized to test the system under more realistic conditions.

Implementing piezoelectric cantilevers from our project partner MacroNano ${ }^{\circledR}$ is a further purpose to be accomplished.

Concerning the overall goal of the project a proof of principle for a wireless, intelligent and energy self-sufficient implant will be done.

\section{ACKNOWLEDGMENTS}

The project has been sponsored by the German Federal Ministry of Education and Research (BMBF) in the funding program "Intelligent Implants".

\section{REFERENCES}

[1] Mide Technology, "PIEZOELECTRIC ENERGY HARVESTERS," Data Sheet, pp. 1-24, 2010. [Online]. Available: http://www.mide.com/pdfs/Volture_Datasheet_001.pdf

[2] G. D. Szarka, S. Member, B. H. Stark, and S. G. Burrow, "Review of Power Conditioning for Kinetic Energy Harvesting Systems," IEEE TRANSACTIONS ON POWER ELECTRONICS, vol. 27, no. 2, pp. 803-815, 2012.

[3] S. Priya and D. J. Inman, Energy Harvesting Technologies. Springer, 2009.

[4] D. Guyomar and M. Lallart, "Recent Progress in Piezoelectric Conversion and Energy Harvesting Using Nonlinear Electronic Interfaces and Issues in Small Scale Implementation," Micromachines, vol. 2, no. 2, pp. 274-294, Jun. 2011. [Online]. Available: http://www.mdpi.com/2072-666X/2/2/274/

[5] A. Hofmann, D. Laqua, and P. Husar, "Piezoelectric Energy Harvesting as Opportunity of Powering Intelligent Implants and Prostheses," Tagungsband des Power and Energy Student Summit 2012, no. figure 2, pp. 2-5, 2012.

[6] L. Technology, "Ultralow Voltage Step-Up Converter and Power Manager FeaTures LTC3108 absoluTe MaxiMuM raTings," Data Sheet, pp. 1-22, 2011. [Online]. Available: http://cds.linear.com/docs/Datasheet/3108fa.pdf

[7] — "LTC4070 - Li-Ion/Polymer Shunt Battery Charger System," Data Sheet, pp. 1-16, 2010. [Online]. Available: http://cds.linear.com/docs/Datasheet/4070fc.pdf

[8] EnerChip, "CBC050 Solid State Energy Storage," Data Sheet, 2010. [Online]. Available: www.cymbet.com/pdfs/DS-72-01.pdf

[9] Texas Instruments, "MSP430F22x2 MSP430F22x4," Data Sheet, no. July 2006, 2011. [Online]. Available: http://www.ti.com/lit/ds/symlink/msp430f2274.pdf

[10] - "TMP20," Data Sheet, no. December, 2009. [Online]. Available: http://www.ti.com/lit/ds/symlink/tmp20.pdf 